\title{
Fibrinolysis of experimental subretinal haemorrhage without removal using tissue plasminogen activator
}

\author{
Lawrence S Morse, Jeffrey D Benner, Leonard M Hjelmeland, Maurice B Landers, III
}

Department of Ophthalmology, University of California, Davis, Sacramento, California, USA

L S Morse

J D Benner

M B Landers, III

Department of Biochemistry and Biophysics, and Biological Chemistry,

University of California, Davis, Sacramento,

California, USA

L M Hjelmeland

Correspondence to: Lawrence S Morse, $\mathrm{MD}$, $\mathrm{PhD}$, Department of Ophthalmology, University of California, Davis, 1603 Alhambra Blvd, Sacramento, CA 95816, USA.

Accepted for publication 11 March 1996

\begin{abstract}
Aims/background-Human recombinant tissue plasminogen activator (rt-PA) fibrinolysis of subretinal haemorrhage with concomitant removal has been shown to reverse the natural history of photoreceptor degeneration in experimental subretinal haemorrhages if evacuated within 7 days. The aim of the study was to determine whether fibrinolysis of subretinal haemorrhage without concomitant removal would offer a simpler approach with similar photoreceptor sparing.

Methods-A neodymium YAG laser was used to create experimental subretinal haemorrhages beneath the holangiotic retina of the cat. Tissue plasminogen activator $(10 \mu \mathrm{g} / \mathrm{ml})$ was injected into 4 day old subretinal haemorrhages to evaluate its effect on altering the natural history of retinal degeneration. Light and electron microscopy were used to study the histopathological effect.
\end{abstract}

Results-The injection of rt-PA into large 4 day old subretinal haemorrhages without concomitant removal did not alter the natural history of retinal degeneration. In fact, a second focus of retinal degeneration occurred at a gravity dependent inferior site where the subretinal haemorrhage had migrated.

Conclusions-There was no therapeutic benefit from the injection of rt-PA into subretinal haemorrhages without concomitant removal in this cat model.

(Br F Ophthalmol 1996;80:658-662)

Subretinal haemorrhage is a devastating complication of choroidal neovascularisation, choroidal rupture, and other less common disease entities. ${ }^{1}{ }^{2}$ Previous studies have described the toxic effects of experimental subretinal haemorrhage on the merangiotic and holangiotic retinas of animals. ${ }^{3-7}$ Our laboratory has shown that fibrin plays an important role in the early outer retinal degeneration associated with these haemorrhages. ${ }^{7}$ The natural history of large, untreated subretinal haemorrhages suggests a progressive, irreversible degeneration of the outer retina and the retinal pigment epithelium (RPE) occurs between 10 and 14 days in the cat model. ${ }^{?}$

Recent technical advances in vitreoretinal surgical techniques have made it possible to remove blood from the subretinal space. ${ }^{2}$ 8-14 Experimental work has demonstrated the feasibility of using human recombinant tissue type plasminogen activator (rt-PA) in the subretinal space to limit fibrin induced injury. ${ }^{4}{ }^{6}{ }^{7}{ }^{15-18}$ In the experimental cat model, tPA assisted surgical removal of subretinal haemorrhages within 7 days resulted in preservation of the photoreceptor-RPE complex. ${ }^{4}{ }^{16}{ }^{18}$ This therapeutic window has also been confirmed in human clinical series of submacular haemorrhage removal with rtPA. ${ }^{19}{ }^{20}$ The purpose of this study was to assess whether fibrinolysis with subretinal injected tPA alone, without surgical removal of the subretinal clot, would also prevent outer retinal toxicity in 4 day old experimental subretinal haemorrhages. We chose 4 day old subretinal haemorrhages because this time point should demonstrate preservation of photoreceptor morphology if fibrinolysis alone is effective and because most cases of acute submacular haemorrhages could be treated within this time frame.

\section{Materials and methods}

METHODS

Commercially prepared human recombinant tissue type plasminogen activator (Activase Genentech, Inc, South San Francisco, CA, USA) was reconstituted and stored at $-80^{\circ} \mathrm{C}$ as previously described. ${ }^{15}$ Before each use, the rt-PA was thawed and diluted in balanced salt solution to a concentration of $10 \mu \mathrm{g} / \mathrm{ml}$. The activity of the rt-PA was $582 \mathrm{IU} / \mu \mathrm{g}$.

Domestic cats weighing $2-5.5 \mathrm{~kg}$ were used in this study, adhering to the ARVO resolution on the use of animals in research and the NIH guide for the care and use of laboratory animals. A normal complete blood count, platelet estimate, bleeding time, prothrombin time, and partial thromboplastin time were required for entry into the study. Routine pre and postoperative veterinary and eye care was performed as previously described. ${ }^{\text {? }}$

CREATION OF SUBRETINAL HAEMORRHAGES

Subretinal blebs were created in the tapetal retina with a glass micropipette stabilised with a stereotactic micro-manipulator. ${ }^{7}$ Glass micropipettes of $550 \mu \mathrm{m}$ in outside diameter (In Vitro Dynamics, Rahway, NJ, USA) were fabricated to a $40-60 \mu \mathrm{m}$ outside diameter tip as previously described. ${ }^{7}$ Balanced salt solution (BSS) was infused in the subretinal space at a rate of 5 to $10 \mu \mathrm{l} / \mathrm{min}$ for $1-2$ minutes to create a subretinal bleb. To create subretinal haemorrhages, a neodymium YAG laser (VisuLas 

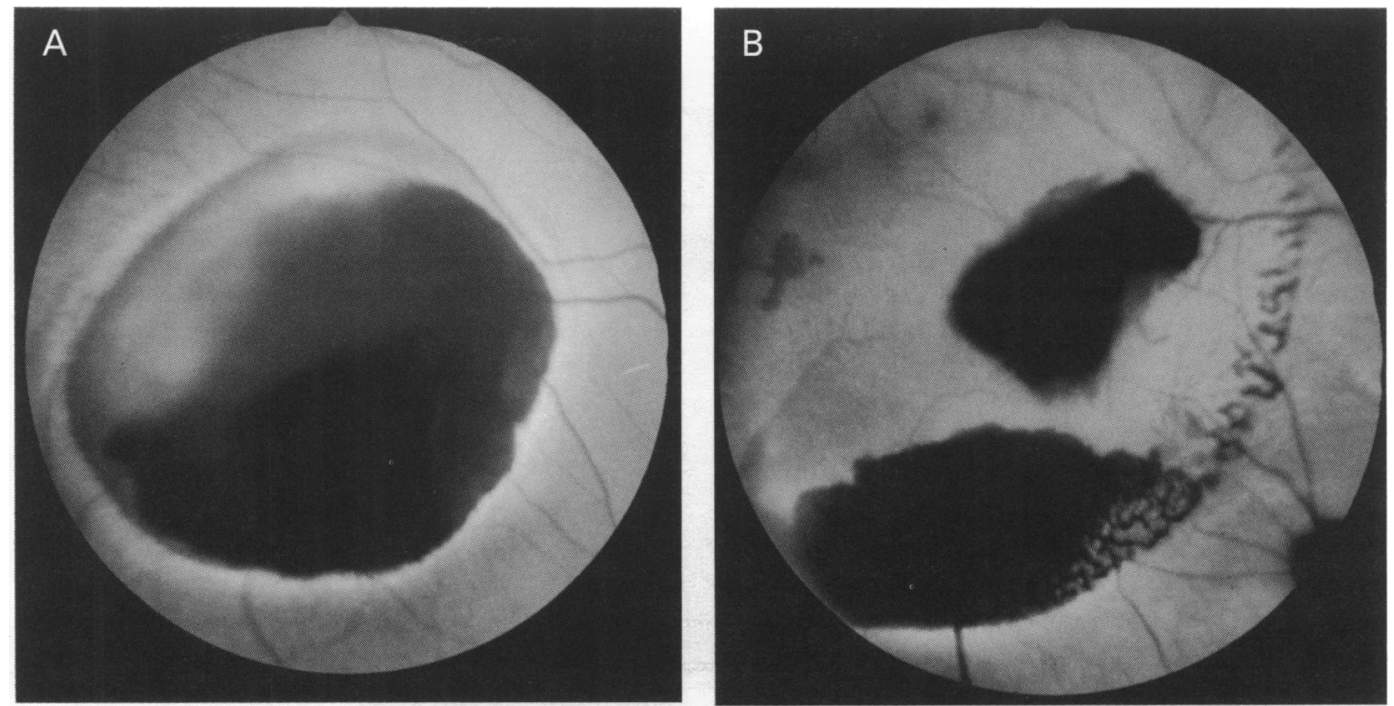

Figure 1 (A) Fundus photograph of untreated large subretinal haemorrhage 30 minutes after formation. (B) Fundus photograph of untreated same eye, 4 days later. Note the central coagulum and the gravity dependent layering of the red blood cells.

YAG, Zeiss, Germany) was focused just inside the edge of the bleb and the aiming beam was slightly defocused before discharging the laser. ${ }^{16}$ Approximately $2-10$ laser shots from 10 to $25 \mathrm{~mJ}$ were required to create a subretinal haemorrhage. Using this technique, subretinal haemorrhages in eight eyes in eight cats were formed. Indirect ophthalmoscopy and fundus photography were performed at selected time points. The sizes of the subretinal haemorrhages were measured from the fundus photographs in terms of optic disc diameters (one disc area of cat $=0.9 \mathrm{~mm}$ ). Using this technique, seven large subretinal haemorrhages

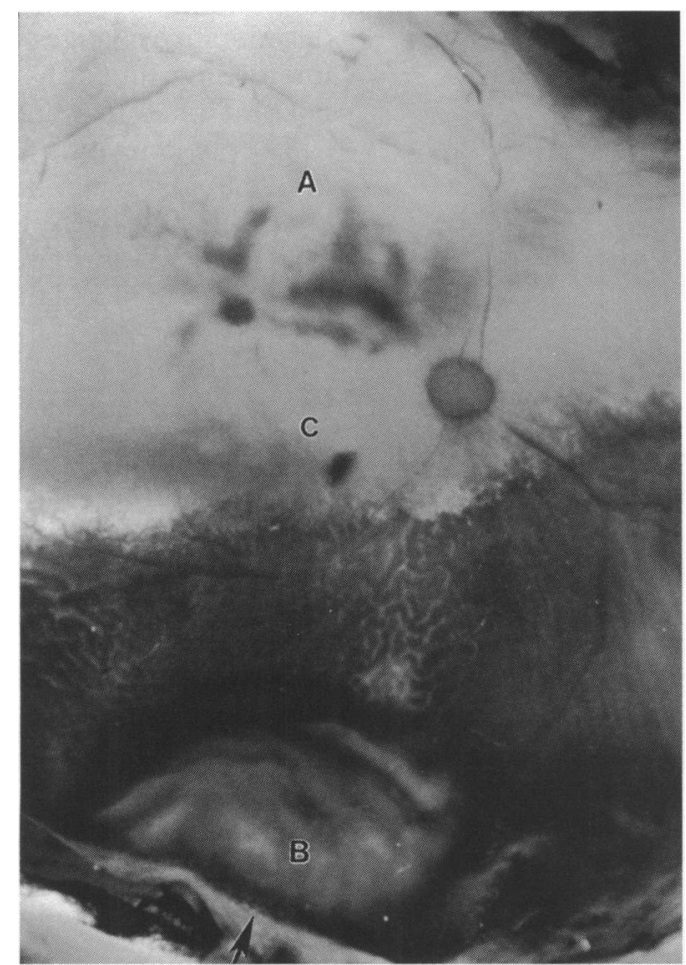

Figure 2 Gross photograph of eye 14 days after tissue plasminogen activator was injected into a large subretinal haemorrhage $\geqslant 3$ disc diameters. Note the large blood mass that has migrated inferiorly almost to the ora serrata (arrowhead). The letters correspond to the histopathological sections in Figure 3.
( $\geqslant 3$ disc diameters, DD) (Fig $1 \mathrm{~A})$ and one small subretinal haemorrhage $(\leqslant 2 \mathrm{DD})$ were created.

INIECTION OF rt-PA INTO THE SUBRETINAL HAEMORRHAGE

The recombinant tissue plasminogen activator $(10 \mu \mathrm{g} / \mathrm{ml})$ was infused into the subretinal space of 4 day old large subretinal haemorrhages in four eyes through a glass micropipette for $21 / 2-5$ minutes at $20 \mu \mathrm{l} / \mathrm{min}$ for a total dose of $0.5-1.0 \mu \mathrm{g} \mathrm{rt}-\mathrm{PA}$. The volume of rt-PA injected was dependent on the size of the subretinal bleb needed to completely cover the subretinal haemorrhage.

TISSUE PROCESSING

For euthanasia, animals were premedicated with an intramuscular injection of ketamine hydrochloride $(33 \mathrm{mg} / \mathrm{kg})$, then given an intravenous injection of pentobarbitone $(85 \mathrm{mg} / \mathrm{kg})$, followed by immediate enucleation. Eyes were incised at the pars plana and immersed in $2.5 \%$ glutaraldehyde, $1.5 \%$ paraformaldehyde in 0.1 $M$ sodium cacodylate buffer, $\mathrm{pH} 7.4$, at $4^{\circ} \mathrm{C}$. After 15 minutes, the eye was hemisected and both the anterior and posterior portions were once again immersed in fixative for a period of 24 hours. The fixed posterior eye cups were dissected to isolate the area of interest by careful anatomical correlation with intraoperative video prints and postoperative photographs. The resulting tissue blocks were then bisected through the centre of each bleb, and each half was processed for either light or electron microscopy.

\section{LIGHT MICROSCOPY}

Tissues were dehydrated in graded ethanol and embedded in hydroxy ethyl glycol methacrylate resin (Polysciences Inc, Warrington, PA, USA). Sections of 2-3 $\mu \mathrm{m}$ were cut on an LKB Ultrotome III (Stockholm) and stained with the Richardson's stain. Photomicrographs were obtained with a Zeiss photomicroscope. 
A
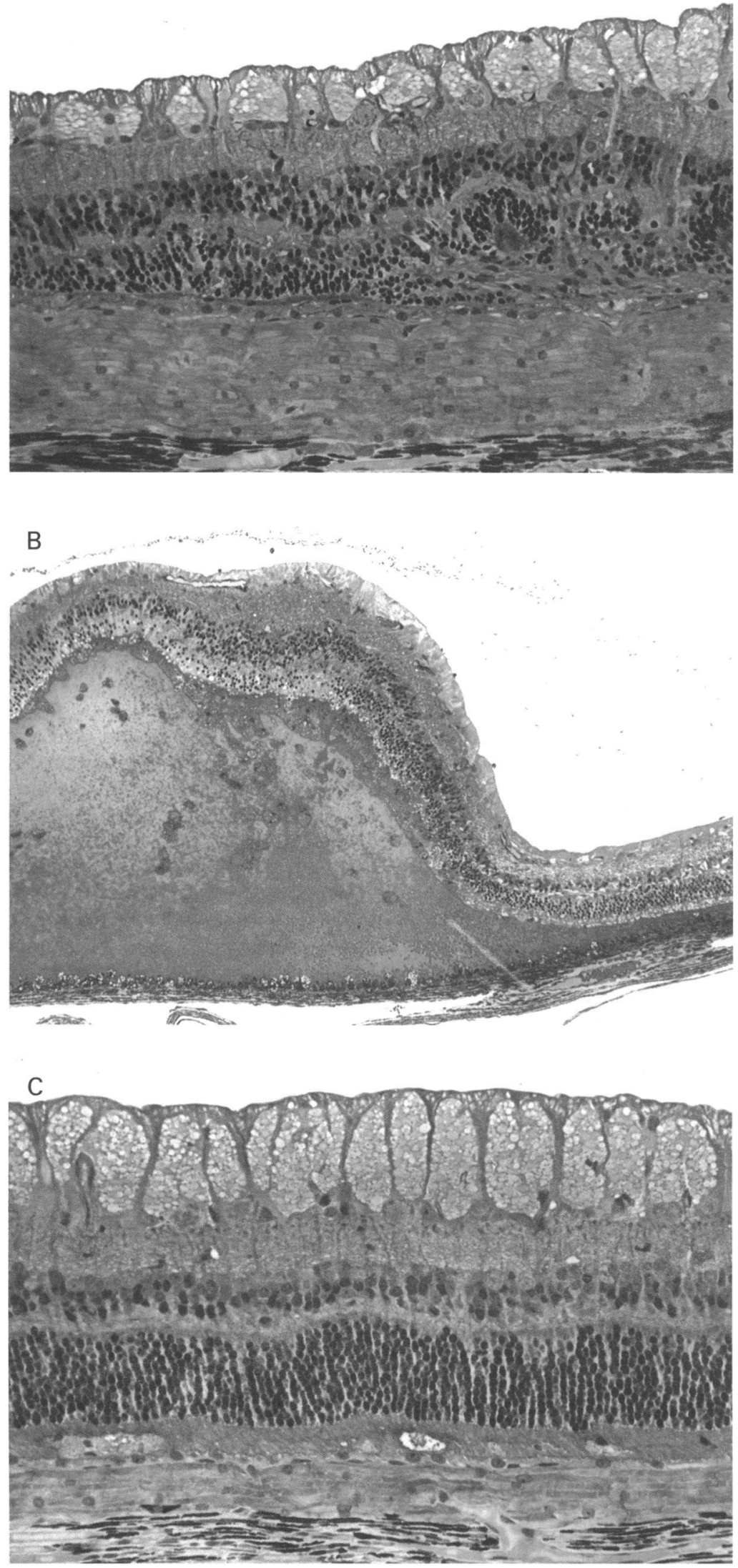

Figure $3(A)$ Photomicrograph of area indicated by ' $A$ ', in Figure 2. The photoreceptor outer and inner segments are absent, the cell bodies of the outer nuclear layer are pyknotic and reduced in number. A marked glial response within the subretinal space is present (Richardson's stain, original magnification $\times 195$ ). (B) Light photomicrograph of area indicated by ' $B$ ', in Figure 2 . Note the degeneration of the outer retina overlying the blood mass that migrated inferiorly. The outer nuclear layer is markedly atrophic with evidence of gliosis and loss of photoreceptor cell bodies (Richardson's stain, original magnification $\times 77)$. (C) Light photomicrograph of ' $C$ ', in Figure 2. Note minimal degeneration of the outer retina. These changes are similar to those found in balanced salt solution blebs in the cat that resolve spontaneously in 2 days (Richardson's stain, original magnification $\times 195$ ).

\section{Results}

FIBRINOLYTIC THERAPY/CLINICAL RESULTS

Three large untreated subretinal haemorrhages were evaluated histopathologically at 2 and 4 weeks by light microscopy. These animals served as controls to confirmed previously published observations of outer retinal and RPE degeneration ${ }^{16}$ (data not shown).

Four large subretinal haemorrhages $(\geqslant 3 \mathrm{DD}$ from four eyes) and one small subretinal haemorrhage ( $\leqslant 2 \mathrm{DD}$ from one eye) were injected with $10 \mu \mathrm{g} / \mathrm{ml}$ of $\mathrm{rt}-\mathrm{PA}$ into the subretinal space on the fourth day after the subretinal haemorrhage formation (Fig lB). In the large subretinal haemorrhages treated with rt-PA, the subretinal haemorrhages were noted to migrate inferiorly in a gravity dependent fashion beneath the non-tapetal retina within the first 48 hours after injection (Fig 2). On funduscopic examination, the initial subretinal haemorrhage site had only a minimal veneer of subretinal haemorrhage and the retina appeared reattached. When rt-PA was injected into the small subretinal haemorrhage, there was no subretinal migration and the haemorrhage was completely resolved 3 days later.

FIBRINOLYTIC THERAPY/HISTOPATHOLOGICAL RESULTS

Twenty one days after rt-PA was injected into the large subretinal haemorrhage areas (25 days total after subretinal haemorrhage formation), the retina at the initial subretinal haemorrhage site had severe outer retinal degeneration (Fig 3A) similar to that seen in the untreated large subretinal haemorrhages. Severe outer retinal degeneration was also present at the new site where the blood had migrated inferiorly (Fig 3B). Minimal retinal degenerative changes were seen throughout the intervening retina, beneath which the subretinal blood had migrated (Fig 3C).

Twenty one days after rt-PA was injected into the small subretinal haemorrhage, histological results were similar to those of untreated small subretinal haemorrhages as previously described ${ }^{16}$ (data not shown).

\section{Conclusion}

Our study design was designed to mimic clinically relevant haemorrhages in a time frame commonly seen in clinical practice. We had hoped to devise a technique of treating subfoveal haemorrhages without surgical evacuation by simply injecting the fibrinolytic agent into the haemorrhage without the added mechanical manipulations required to aspirate the dissolved clot. Theoretically, this might hasten haemorrhage resorption and/or cause the blood to migrate out of the fovea into the inferior retina. In contrast with previous techniques, ${ }^{4}{ }^{6}{ }^{17}$ the use of the small micropipette reduced and perhaps eliminated the efflux of tPA injected into the subretinal haemorrhages from regressing back into the vitreous cavity. Accordingly, we were able to effect good clot dissolution with both low concentrations and small volume of tPA. Clot dissolution was evident within 20-30 minutes in all eyes examined in this study. Although, the rt-PA 
dissolved the organised blood coagulum and caused it to migrate in a gravity dependent manner to the inferior retina, outer retinal degenerative changes still occurred at the site of the initial subretinal haemorrhage. The intervening retina, under which the subretinal haemorrhage had migrated, showed only minimal changes similar to those seen after retinal reattachment after subretinal bleb formation. ${ }^{16}{ }^{21}$ The retina over the site where the subretinal haemorrhage had migrated showed outer retinal degeneration that was equal in magnitude to those observed at the initial haemorrhage site. Thus, injecting rt-PA into large clotted subretinal haemorrhages without concomitant removal produced retinal degeneration at both the initial and secondary subretinal haemorrhage sites. Different observations were reported by Johnson et $a l^{17}$ who used a different study design which did not mimic an expected clinical situation. In their study, tPA was injected into subretinal haemorrhages immediately after autologous blood was injected trans-sclerally into the subretinal space and then analysed 14 days later. In contrast with our study, no clot formation occurred when rt-PA was injected immediately after to injection of subretinal blood. Additionally, they found better preservation of the outer retinal structures in the region of the initial haemorrhage but extensive destruction to outer retinal structures in the inferior retina where the original non-clotted blood had migrated. More recently, Coll et al ${ }^{2}$ reported that intravitreal injection of rt-PA in the rabbit facilitated fibrinolysis of subretinal haemorrhages. They further reported that the electroretinograms were reduced in these animals, which suggested that retinal damage was not prevented by such intervention. However, because of the differences between the vasculature of the merangiotic rabbit model and the holangiotic cat model, and because no histopathological analysis was performed, a direct comparison of these results with ours is not possible.

There are several possible explanations for the degeneration that occurred at the initial subretinal haemorrhage site even though the blood had quickly migrated away from that site in our model. Because the original clot migrated away from the initial site soon after fibrinolysis had occurred, it seems unlikely that a theoretical metabolic barrier is the cause of outer retinal degeneration. Perhaps the nonmigrating residua of a lysed haemorrhage is toxic to the overlying retina. Toxicity might result from the release of fibrin degradation products and other toxins such as haemoglobin derived iron, methaemoglobin, or plasmin protease, resulting from fibrinolysis. Separate studies have shown that concomitant removal of lysed blood following rt-PA injection into 2-7-day-old subretinal haemorrhages results in preservation of the outer retinal architecture. ${ }^{16-18}$ We do not find histopathological evidence to suggest that initial fibrinolysis is followed by fibrin reformation, resulting in mechanical damage to the outer retina and $\mathrm{RPE}$ as a result of gravity dependent migration.
In previous studies, no evidence of clot migration without fibrinolysis occurred. Additionally, the intervening area between initial clot formation and the resultant gravity dependent migration was normal. This suggests that toxic byproducts may remain in greater abundance at both the initial subretinal haemorrhage site and in the gravity dependent site where the residual subretinal blood had migrated.

The initial size of subretinal haemorrhages strongly correlated with the ultimate degree of outer retinal degeneration as was previously reported. ${ }^{16}$ The untreated small subretinal haemorrhages measuring $\leqslant 2$ DD exhibited spontaneous resolution within the first week with only minimal histopathological outer retinal degeneration. Similar changes have been reported following experimental retinal detachment. ${ }^{18}{ }^{23}$ By comparison, all large subretinal haemorrhages measuring $\geqslant 3 \mathrm{DD}$ required 2-3 weeks for the subretinal blood to reabsorb. Irreversible outer retinal degeneration had occurred by the 14 th day. Thus, the size of the subretinal haemorrhage is a strong predictor of histopathological outer retina degeneration. These data are consistent with clinical observations in humans that small subretinal haemorrhages in patients will reabsorb spontaneously and have a better visual outcome. ${ }^{1}{ }^{21}$ What is not clear from our data is how closely this experimental model relates to the clinical situation of macular subretinal haemorrhages in humans. Although cats and humans both have a holangiotic retinas, the subretinal haemorrhage model in the cat may not exactly mirror the human condition. For example, large subretinal haemorrhages in humans take months to reabsorb, not the 2-3 weeks that was observed in our cat model. Also, no subretinal disciform scarring was found in the cat model after resorption of the subretinal haemorrhage.

In summary, progressive outer retinal degeneration secondary to large subretinal haemorrhages is not reduced by fibrinolysis of the clot alone without concomitant removal of the dissolved haemorrhage byproducts. The results support previous studies that demonstrate early surgical evaluation of large subretinal haemorrhages ( $\leqslant 7$ days old) reduces secondary retinal degeneration and suggest that preservation may be facilitated by removing toxic byproducts which otherwise promote outer retinal and RPE degeneration.

Presented in part before the Association for Research in Vision and Ophthalmology, Sarasota, Florida, May 1991. The study was supported in part by a grant from the US Army Medical Research and Development Command 17-89-C-9026 and in part by a grant from Research to Prevent Blindness. The authors have no proprietary interest in Genentech, Inc or human recombinant tissue type plasminogen activator. 1 Bennett SR, Folk JC, Blodi CF, Klugman M. Factors prognostic of visual outcome in patients with
rhage. Am $¥$ Ophthalmol 1990;109:33-7.

2 Wade E, Flynn HW, Olsen KR, Blumenkranz MS

Nicholson DH. Subretinal hemorrhage management by Nicholson DH. Subretinal hemorrhage management by

3 Glatt H, Machemer R. Experimental subretinal hemorrhage in rabbits. Am $\mathcal{F}$ Ophthalmol $1982 ; 94: 762-73$.

4 Johnson MW, Olsen KR, Hernandez E. Tissue plasminogen activator treatment of experimental subretinal hemorrhage. Retina 1991;11:250-8.

5 Koshibu A. Ultrastructural studies on absorption of experimentally produced subretinal hemorrhage. III Absorption 
of erythrocyte breakdown products and retinal hemosiderosis at the late stage. Acta Soc Ophthalmol fpn 1979;83:386-400.

6 Lewis H, Resnick SC, Flannery JG, Straatsma BR. Tissue plasminogen activator treatment of experimental subretinal hemorrhage. Am f Ophthalmol 1991;111:197-204.

7 Toth CA, Morse LS, Hjelmeland LM, Landers MB. Fibrin directs early retinal damage after experimental subretinal hemorrhage. Arch Ophthalmol 1991;109:723-9.

8 de Juan E Jr, Machemer R. Vitreous surgery for hemorrhagic and fibrous complications of age-related macular rhagic and fibrous complications of age-related

9 Dellaporta A. Retinal damage from subretinal hemorrhage. Am $f$ Ophthalmol 1983;95:568-70.

10 Flynn HW, Davis JL, Parel JM, Lee WG. Applications of a cannulated extrusion needle during vitreo-retinal microsurgery. Retina 1988;8:42-9.

11 Han DP, Mieler WF, Schwartz DM, Abrams GW. Management of traumatic hemorrhagic retinal detachment with pars plana vitrectomy. Arch Ophthalmol 1990;108:1281-6.

12 Hanscom TA, Diddie KR. Early surgical drainage of macular subretinal hemorrhage. Arch Ophthalmol 1987;105: 1722-3.

13 Thomas MA, Halperin LS. Subretinal endolaser treatment of a choroidal bleeding site. Am f Ophthalmol 1990;109: $742-4$.

14 Vander JF, Federman JL, Greven C, Slusher MM, Gabel VP. Surgical removal of massive subretinal hemorrhage associated with age-related macular degeneration. Ophthalmology 1991;98:23-7.
15 Benner JD, Morse LS, Toth CA, Landers MB, Hjelmeland LM. Evaluation of a commercial recombinant tissue-type plasminogen activator preparation in the subretinal space of the cat. Arch Ophthalmol 1991;109:1731-6.

16 Benner JD, Hay A, Landers MB, Hjelmeland LM, Morse LS. Fibrinolytic assisted removal of experimental subretinal hemorrhages within seven days reduces outer retinal degeneration. Ophthalmology 1994;101:672-81.

17 Johnson MW, Olsen KR, Hernandez E. Tissue plasminogen activator thrombolysis during surgical evacuation of experimental subretinal hemorrhage. Ophthalmology 1992; 99:515-21.

18 Toth CA, Hjelmeland LM, Landers MB, MorseLS. Ultramicrosurgical removal of experimental subretinal Ultramicrosurgical removal of experimental subretinal

19 Lewis H. Intraoperative fibrinolysis of submacular hemorrhage with tissue plasminogen activator and surgical drainage. Am $\mathcal{F}$ Ophthalmol 1994;118:559-68

20 Ibanez HE, Williams DF, Thomas MA, Ruby AJ, Meredith TA, Boniuk I, et al. Surgical management of submacular hemorrhage. A series of 47 cases. Arch Ophthalmol 1995;113:62-9.

21 Gillies A, Lahav M. Absorption of retinal and subretinal hemorrhages. Ann Ophthalmol 1983;15:1068-74.

22 Coll GE, Sparrow JR, Marinovic A, Chang S. Effect of intravitreal tissue plasminogen activator on experimental subretinal hemorrhage. Retina 1995;15:319-26.

23 Anderson DH, Guerin CJ, Erickson PA Stern WH, Fisher SK. Morphological recovery in the reattached retina. Invest OphthalmolVis Sci 1986;27:168-83. 